\title{
A QUALIDADE DA EDUCAÇÃO A DISTÂNCIA NA UNISULVIRTUAL: UMA VISÃO DO PROCESSO DE TUTORIA
}

\author{
(THE QUALITY OF DISTANCE EDUCATION IN UNISULVIRTUAL: A VISION OF THE TUTORIAL \\ PROCESS)
}

Angelita Marçal Flores

UnisulVirtual - Universidade do Sul de Santa Catarina (Brasil)

\section{RESUMEN}

O texto apresenta o caminho percorrido em busca da qualidade nos programas de Educação a Distância, ofertados pela UnisulVirtual, com foco no papel de seus educadores, chamados de Tutores. Apresenta-se num primeiro momento a crença de que a busca pela qualidade não é um fator isolado, devendo estar presente em cada processo, valorizando-se especialmente os talentos humanos. Neste cenário, aborda-se o papel desenvolvido pelo Tutor para o bom funcionamento da metodologia de Educação a Distância. Descreve-se uma das estratégias da UnisulVirtual para avançar em qualidade na Educação a Distância, representada por ações permanentes de capacitação dos tutores, seguidas pelo acompanhamento e suporte pedagógico em todas as suas atividades. Por fim, relatam-se os resultados do processo, além de novas perspectivas de atuação.

\begin{abstract}
This paper shows the continuous efforts to reach high quality in distance education at Unisul Virtual programs. These efforts are concentrated on the role of the teachers, called here Tutors. First of all is showed that this quality is not an isolated factor, but in fact it is part of each process taking advantage of human talents. The tutor role in this scenario is essential for the good development of distance education methodology. Therefore the strategies of Unisul Virtual are focused on permanent activities to improve the tutor skills by training, support and pedagogical maintenance. The paper fi-nishes with results and proposals of perspectives and new lines of research.
\end{abstract}

\section{OS PRIMEIROS PASSOS}

Assiste-se uma vertiginosa expansão do conhecimento humano, suportada pelo desenvolvimento nas Tecnologias de Informação e Comunicação (TICs). Isto ocorre, a partir do grande número de informações disponíveis e que podem ser 
transformadas pela experiência humana em insumos de apoio as ações individuais ou coletivas, num processo constante de retroalimentação. Mas o acompanhamento desta evolução não é simples, exige mudanças e investimentos de todos os setores. Segundo Castells (1999, p.127), para que isto seja possível "[...] a cultura e as instituições da sociedade, bem como as empresas e os fatores que interagem no processo produtivo precisam passar por mudanças substanciais". Em uma sociedade centralizada em conhecimentos e informações, a capacidade de processar símbolos ligados a cultura e a educação de seu povo, são requisitos básicos.

Nesse contexto, a educação deve ganhar novos significados e desempenhar um papel ativo na formação da sociedade. Dentre as oportunidades para o desenvolvimento desta ação, encontra-se a Educação a Distância (EaD), em especial de nível Superior, também chamada de Educação Virtual, a qual "[...] tem mostrado os seus benefícios não para substituir a educação presencial, mas, sim, para articular-se com esta [...] A educação superior virtual introduz uma nova modalidade de ensino aprendizagem [...]” (Vianney, Torres \& Silva, 2003, p.9).

No Brasil, a EaD foi regulamentada pelo Ministério da Educação, o qual apresenta uma definição que introduz o conceito de auto-aprendizagem, do uso de métodos e recursos nesta modalidade (Idem).

Consciente deste cenário, a Universidade do Sul de Santa Catarina (Unisul), em 1998 institucionalizou suas primeiras ações de Educação a Distância, entendendo que esta é apenas uma outra modalidade de estudos, devendo estar integrada as demais ações institucionais.

Desde 2001, UnisulVirtual, é o campus responsável pelo planejamento e implementação da Educação a Distância ofertada pela Unisul nos níveis de graduação, pós-graduação e capacitação ${ }^{1}$. O primeiro curso a distância, no nível de capacitação, deu-se em 2001, com 50 alunos e em 2006 já são aproximadamente 6000 alunos.

Este crescimento implica em maiores responsabilidades com um objetivo permanente: a qualidade de seus produtos e serviços. Para tanto, investe-se no planejamento e revisão constante de todos os processos, envolvendo seus profissionais e alunos, orientados pelas diretrizes presentes na Universidade. Dentro desta visão de qualidade, todas as atividades são consideradas essenciais e devem ser desempenhadas com eficiência.

Para enfrentar e superar estes desafios são necessários recursos, interligados e interdependentes, tais como um modelo pedagógico adequado às necessidades, um suporte tecnológico sintonizado com os objetivos e talentos humanos capacitados e motivados. Tratando-se de educação, um dos elementos humanos centrais neste contexto é a figura responsável pela orientação dos alunos nas atividades de estudo a distância, nomeado de Tutor. 
Sabe-se que uma das dificuldades enfrentadas pelas instituições educacionais que oferecem a modalidade a distância é manter em seu quadro, docentes capazes de atuar com um modelo pedagógico diferenciado, lidar com as TICs e superar os demais desafios da educação no século XXI. Mesmo com a oferta programas de capacitação inicial, muitos ainda não conseguem transpor os conhecimentos vistos durante a formação para o dia-a-dia das salas de aula virtuais. Torna-se necessário ir além da capacitação inicial.

Na UnisulVirtual o caminho escolhido para minimizar estas dificuldades foi a formação de uma equipe, da qual esta autora é integrante, composta por profissionais com formação multidisciplinar e experiência nas áreas de tecnologias aplicadas à Educação e em Educação a Distância.

Esta equipe é responsável por dinamizar as ações de capacitação inicial, suporte pedagógico e capacitação continuada dos tutores. O objetivo deste trabalho é descrever e analisar estas ações, propiciando ao leitor uma visão dos procedimentos adotados para realizá-las e de seus resultados até o momento.

Para isto, apresenta-se a seguir uma breve visão do sistema tutorial da UnisulVirtual e nele, o papel do Tutor. Num segundo passo resgate-se a capacitação inicial dos tutores para, em seguida, descrever as ações de acompanhamento antes, durante e depois das atividades que envolvem o período de docência em cursos à distância na UnisulVirtual. Por fim, apresentam-se as ações de capacitação continuada, dentre outras considerações.

Este trabalho pretende ser uma contribuição modesta ao necessário esforço coletivo, já em curso nos muitos horizontes. Vale ressaltar que estas linhas são resultantes da vivência desta autora, de sua inteira responsabilidade, não havendo vínculo com uma análise institucional.

\section{SISTEMA TUTORIAL NA UNISULVIRTUAL E SEUS AGENTES}

No modelo de Educação a Distância (EaD) desenvolvido pela UnisulVirtual, utiliza-se de uma combinação de diferentes mídias na produção dos materiais didáticos, destinados a facilitar a relação ensino-aprendizagem e motivar o auto-aprendizado e o trabalho colaborativo. Aplica-se periodicamente, instrumentos de avaliação institucional, o que gera uma revisão contínua de suas ações.

O suporte tecnológico, com o desenvolvimento de um Ambiente Virtual de Aprendizagem (AVA) próprio, proporciona a flexibilidade e a agilidade necessárias perante as mudanças implantadas constantemente no modelo. A expressão AVA, "tem sido utilizada, de modo geral, para se referir ao uso de recursos digitais de comunicação utilizados para mediar a aprendizagem" (Valentini \& Soares, 2006).

No centro do processo encontra-se o aluno, cercado por um sistema tutorial, que pode ser definido como, "[...] a organização de profissionais e de procedimentos ad- 
ministrativos, pedagógicos e comunicacionais que buscam atender de forma direta às necessidades dos alunos na modalidade a distância. É composto por uma equipe que atua cooperativamente no cumprimento de suas funções e responsabilidades para possibilitar a gestão da aprendizagem" (Sartori \&Roesler, 2005, p.50).

Dentro deste sistema, a atividade de orientação on-line é fundamental e deve haver uma preocupação permanente com seu agente principal, o Tutor, "[...] um especialista em área relacionada à formação do curso no qual atua” (Idem, p.52). Suas responsabilidades são de acompanhar diretamente o processo de aprendizagem dos alunos do curso, nas avaliações e orientação a distância, bem como nos encontros e avaliações presenciais, quando houver (UnisulVirtual, 2005a).

Os Tutores são os docentes da própria Universidade, atuantes na Educação Presencial, sendo, a maioria, mestres ou doutores. O processo de seleção, capacitação, acompanhamento e registro das ações dos Tutores, além das suas sugestões e críticas, são acompanhados pela direção, coordenadores de curso e demais equipes.

\section{A CAPACITAÇÃO INICIAL DOS TUTORES}

Compreende-se que a capacitação de educadores para atuarem com TICs deve ir além dos conhecimentos sobre os aspectos tecnológicos, abrangendo a reflexão das questões pertinentes a um processo educativo diferenciado, não mais centrado no educador. É importante que o educador, perceba a “[...] dimensão espacial que ultrapassa os limites das paredes da escola, considerando a dinâmica de relações entre espaço e tempo, conectada com a sociedade, escola eindivíduo que estão sendo e que estão para ser" (Hernandes, 2005).

Para atender a este cenário e a realidade da Unisul, partiu-se do entendimento que a metodologia e a tecnologia, além de serem instrumentos para conduzir um projeto de capacitação, são também objetos de estudo dessa formação. Ressalta-se que, para uma proposta de formação de educadores irem além de uma idéia de formação reducionista é indispensável procurar-se por meio da EaD, constituir um espaço em que as teorias estudadas sejam ao mesmo tempo ferramentas para compreender, agir e modificar a sua prática pedagógica (Roesler, Costa \& Flores, 2005). Assim, os cursos ofertados na UnisulVirtual para a preparação dos professores que atuarão com as NTIC na educação presencial ou a distância, são fundamentados numa metodologia prático-reflexiva.

Desde 2000, inúmeros cursos de capacitação de educadores foram ofertados pela UnisulVirtual. O primeiro foi um programa para "Preparação de autores e tutores", composto por uma parte geral sobre EaD, seguida do processo de autoria e tutoria. De 2002 a 2003 foram ofertados somente cursos para o uso do Ambiente Virtual de Aprendizagem no Apoio Pedagógico à Educação Presencial. Os resultados deste processo foram bastante promissores, uma vez que auxiliaram na qualidade da educação presencial e na disseminação da cultura de projetos institucionais de cunho virtual, em especial da EaD. Até o final de 2003, 413 educadores já haviam passado 
por algum tipo de capacitação ofertada pela UnisulVirtual e mais de 400 salas foram abertas no Ambiente Virtual de Aprendizagem para o apoio pedagógico on-line a educação presencial.

A partir do segundo semestre de 2003, teve inicio na UnisulVirtual, a oferta de cursos superiores a distância. Desenvolveu-se então, no inicio de 2004, um curso específico, denominado "Capacitação para Tutores". Com o objetivo de preparar os docentes para o exercício da função de Tutor na UnisulVirtual, este curso com carga de $24 \mathrm{~h}$, duas horas num primeiro encontro presencial e as demais totalmente on-line, capacitou neste primeiro ano, 123 educadores. Considerando o total de inscritos, este número representa um índice médio de conclusão de $60 \%$.

Em 2005, a partir das observações realizadas pela equipe responsável, sugestões dos tutores e demais envolvidos, o curso, recebeu alterações, visando, também à adequação das mudanças do Ambiente Virtual de Aprendizagem e da metodologia de Educação a Distância na UnisulVirtual. Em 2005, 130 docentes concluíram este curso, representando $75 \%$ dos inscritos. Este aumento em relação a 2004 pode ser atribuído ao aprimoramento do feedback da equipe de formadores, com o envio de cartas mais freqüentes aos participantes contendo mensagens personalizadas, elogiando as tarefas realizadas e incentivando a continuidade do curso (Unisul, 2006).

Considerando-se o histórico do processo de capacitação até 2005, além do depoimento dos professores, alguns pontos importantes foram observados (Idem):

- na maioria dos casos dos docentes que desistiram do curso, alegaram não ter tempo disponível para a capacitação e/ ou tutoria devido ao excesso de atividades no momento. Este fator, pode ser visto como um mecanismo de seleção de tutores, ao observarmos que se não há tempo para capacitar-se, dificilmente terá disponibilidade para a tutoria.

- muitos docentes iniciaram o curso quando este já estava em andamento, não participando do encontro presencial inicial, ficando um pouco dispersos no processo.

- necessidade de incrementar o caráter pedagógico/reflexivo no curso de capacitação de tutores, bem como nos materiais impressos que os acompanham, levando em conta as sugestões dos tutores e observações da equipe de capacitação.

Em 2006, considerando-se novamente todas as observações da equipe de formadores, a coleta de críticas e sugestões dos tutores, o curso de capacitação recebeu uma nova versão, estreitando-se ainda mais a parceria com as equipes de Design Instrucional e de Avaliação de Aprendizagem no seu desenvolvimento. O material impresso que acompanha o curso foi remodelado e a carga horária passou para 40h. Houve também a mudança da forma de entrada dos docentes no curso. Até 2005 participavam da capacitação, somente docentes indicados pelas coordenações de curso para atuarem na Tutoria, a partir de 2006, as inscrições foram abertas a todos os docentes da Unisul. Neste ano, até o mês de abril, já foram capacitados 108 tutores. 
Mesmo obtendo resultados positivos, a equipe responsável permanece atenta e discute constantemente entre seus membros, com a direção da UnisulVirtual, coordenadores de curso, tutores e demais equipes, as necessidades de melhorias neste processo.

\section{ACOMPANHAMENTO E SUPORTE PEDAGÓGICO AS ATIVIDADES DE TUTORIA}

Sabendo que a $\mathrm{EaD}$ é uma nova forma de atuar, observa-se a necessidade dos Tutores de receberem apoio no desenvolvimento de suas atividades, seja no âmbito da prevenção ou da resolução de problemas que surgem devido as limitações de um modelo em implantação, sujeito as mudanças periodicamente.

Assim, a mesma equipe responsável pela capacitação inicial, realiza atividades de acompanhamento e apoio pedagógico aos tutores em atuação. Os procedimentos realizados incluem a integração com as outras equipes para recebimento e confirmação de informações, o acesso a todas as salas no Ambiente Virtual de Aprendizagem e o contato, quase diário, com os Tutores. A equipe mantém um endereço de e-mail exclusivo para comunicar-se com os tutores e demais integrantes da UnisulVirtual.

Desde o primeiro semestre de 2005, quando a equipe iniciou o registro das atividades de acompanhamento e apoio pedagógico, houve crescimento significativo do número de turmas (Fig. 1). Estes números seguem naturalmente o aumento de alunos na UnisulVirtual, sendo acompanhadas 252, 357 e 630 turmas respectivamente nos semestres de 2005A, 2005B e 2006A.

Figura 1: Número de turmas acompanhadas no ano de 2005 e no primeiro semestre de 2006.

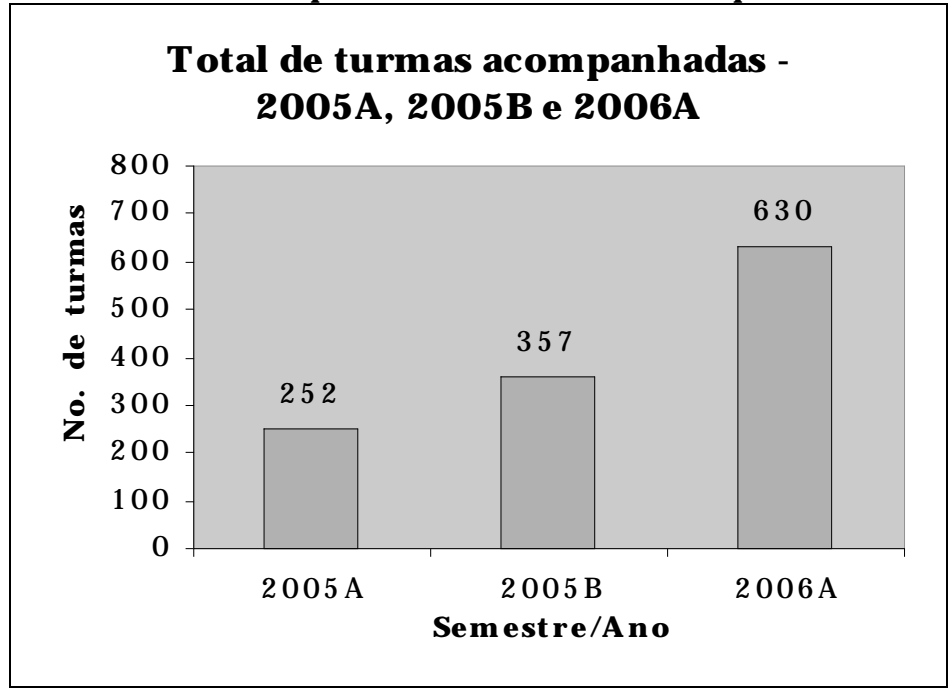


Vale ressaltar que estes são os números totais de cada semestre e não representam simultaneidade de oferta. O gráfico (fig.34) mostra um exemplo e permite visualizar como se dá o acompanhamento do número de turmas semanalmente em paralelo.

Para a execução destas tarefas, é mantido um banco de dados das turmas ${ }^{2}$ ofertadas a cada semestre, em todos os cursos e disciplinas a distância, registrando-se ao longo dos meses, todas as informações referentes aos procedimentos executados pelos tutores, em cada turma. Até 2005, estes registros eram realizados manualmente, acessando cada uma das salas no AVA, verificando as ocorrências (por exemplo, o número de perguntas sem resposta) e registrando estes dados na planilha.

Figura 2: Número de turmas acompanhadas simultaneamente por semana no segundo semestre de 2005.

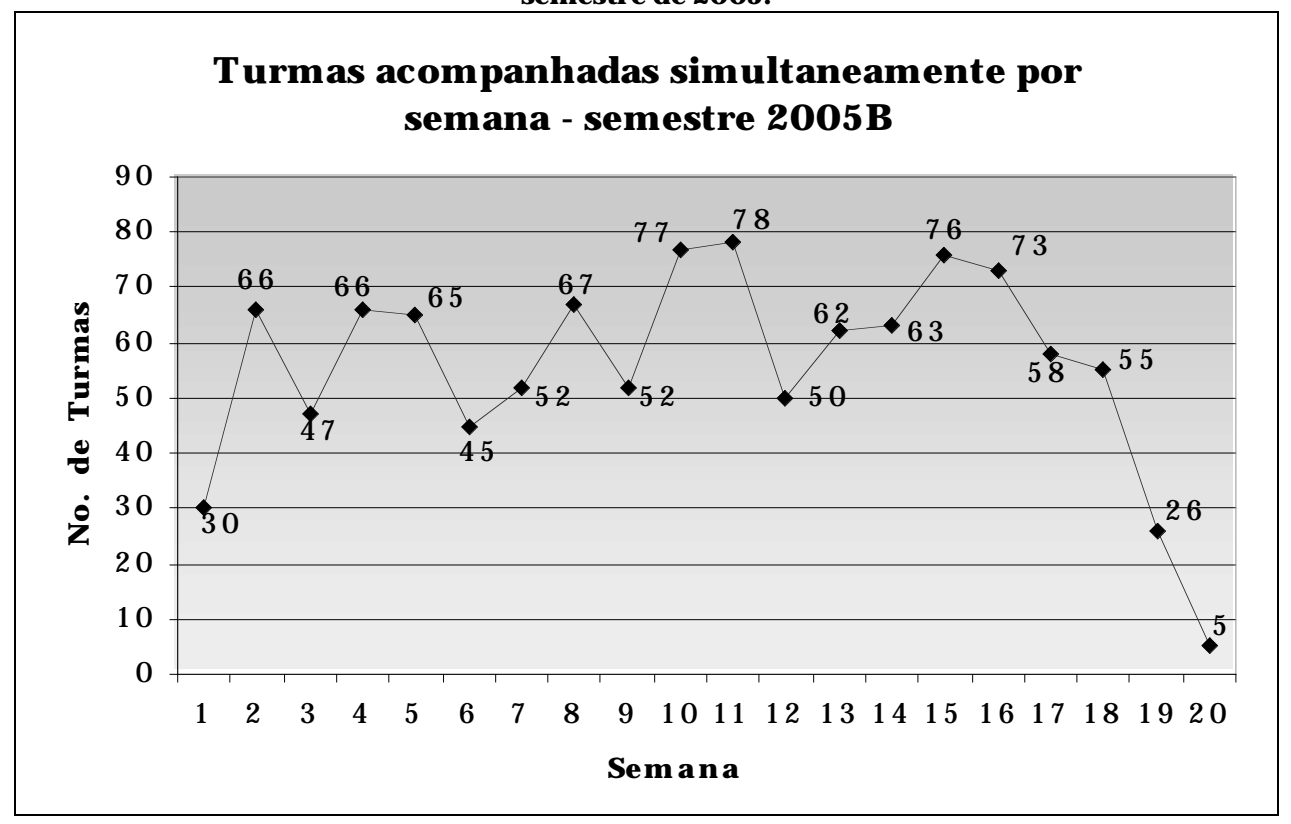

Em 2006, a equipe de tecnologia da UnisulVirtual desenvolveu relatórios para realizassem os registros de acompanhamento dos tutores automaticamente, exportando-os posteriormente para o formato de planilha, o que permite o seu uso e processamento para a continuidade das atividades. Estes dados correspondem aos parâmetros numéricos dos prazos que o tutor tem para desenvolver algumas tarefas, como por exemplo, responder a uma dúvida do aluno, fazer a avaliação de uma atividade a distância, publicar uma mensagem na área de comunicados, enviar mensagem de para o e-mail dos alunos e outras. Estas ações são monitoradas pela equipe visando o atendimento adequado aos alunos, dentro dos prazos estabelecidos e com uma participação do tutor que seja suficiente para manter os alunos informados e motivados para a aprendizagem.

As principais ações do apoio pedagógico são: 
1. Preventivas: partem da ECAP, tendo em vista padrões e experiências sobre os problemas mais comuns no processo de tutoria. Enviam-se mensagens aos tutores para todos os eventos importantes que ocorrerão antes, durante e depois da oferta de uma disciplina, lembrando-os sobre os prazos e as ações a serem realizadas. Os momentos de prevenção são: antes do início, últimos dias de oferta, no inicio do "plantão pedagógico"3, antes do encontro de revisão (se houver) e de avaliação presencial e após a realização das avaliações presenciais. Esporadicamente, também se enviam mensagens a todos os professores tutores atuantes, motivando-os, informando quaisquer mudanças no sistema, orientações pedagógicas e propostas de debates sobre o processo de tutoria. Um exemplo de atividade preventiva que a equipe realiza é a recordação aos tutores dos prazos de publicação de notas. É possível observar no trecho apresentado (quadro 1) que na mensagem enviada informa-se a disciplina e curso a que se refere, o objetivo, a problemática apresentada, suas implicações e no caso da prevenção, recorda a ação que o professor Tutor deverá realizar.

\section{Quadro 1: Mensagem preventiva para informar mudanças no modelo e recordar a} publicação das notas.

"Memória est thesaurus ómnium rerum et custos. (A memória éo tesouro e a guardiã detodas as coisas) Cícero, De oratore, 1, 5, 18

Prezado (a) Tutor (a)

Primeiramente gostaríamos de agradecer sua dedicação durante o oferecimento da disciplina de. do Curso

Neste semestre foram implementadas mudanças que interferem diretamente no volume e tempo de chegada das avaliações presenciais dos locais de prova até a UnisulVirtual, além da alteração na forma de publicação das Notas pelos tutores ea sua visualização pelos alunos, que passam a ser realizadas no sistema PeopleSoft. Perante este novo contexto, pedimos a sua colaboração, atentando para as seguintes recomendações:

Colocamos a equipe a sua disposição para esclarecimentos.

Cordialmente,

Equipede Capacitação e Apoio Pedagógico à Tutoria

UnisulVirtual"

2. Corretivas: partem da ECAP, em virtude das informações provenientes do acompanhamento das ações dos tutores nas salas no AVA e da monitoria (uma vez que esta atende diretamente aos alunos). Caso observe-se a não conformidade pedagógica, de linguagem, de atrasos nos prazos ou outras dificuldades, enviam-se mensagens aos tutores lembrando as ações não realizadas antes, durante ou após a oferta de uma disciplina. Estes momentos são: no primeiro dia de oferta, a cada dois dias úteis durante o período de oferta da disciplina, no plantão pedagógico e após a realização das avaliações presenciais. 
No trecho a seguir, é possível observar que mesmo nas mensagens que visam solicitar ao tutor a realização de ações que ele deixou de cumprir, a construção da mensagem e a linguagem utilizada conduzem a uma relação de afetividade entre a equipe e tutora. O “tom” da mensagem procura elogiar o que está bom, recordar o que precisa ser feito ou melhorar e por fim, mostrar a intenção da equipe de auxiliar o processo de tutoria.

\section{Quadro 2: Mensagem corretiva para informar pendências e recordar as responsabilidades} da tutora.

Prezada Professora

Tudo bem?

Estamos acompanhando a tutoria da sua disciplina de e, com muita satisfação, percebemos que tudo transcorre bem: o mural atualizado, os fóruns disponibilizados aos alunos.

Gostaríamos somente de lembrá-la que na ferramenta "Tutor" existe uma pergunta de um aluno aguardando sua reposta... embora esteja ainda em tempo hábil, vale reforçar...

De igual forma, sugerimos que as mensagens publicadas no mural, sejam também enviadas por e-mail para toda a turma, no intuito de estreitar ainda mais a relação entre tutor ealuno.

Nosso objetivo é auxiliá-la nesse processo de educação à distância... o sucesso de todos se configura no sucesso da Unisul Virtual!

Atenciosamente,

Equipede Capacitação e Apoio à tutoria.

UnisulVirtual

3. De atendimento: são as respostas da equipe para as diversas mensagens recebidas dos tutores. As mensagens contêm dúvidas pedagógicas ou de uso dos recursos do AVA, sugestões e críticas ao processo, agradecimentos, pedido de informações sobre como agir em determinadas situações, como responder perguntas de alunos e outras.

É importante ressaltar que ao ingressar na atividade de tutoria, os docentes estão conscientes da existência destas ações de acompanhamento, compreendem e reconhecem, em sua maioria, a importância deste trabalho. Isto pode ser observado, a partir do teor das suas respostas após o recebimento das mensagens do apoio pedagógico e nos questionários que são aplicados aos tutores ao final de cada semestre para avaliação institucional.

Em pesquisa realizada no segundo semestre de 2005 (Unisul, 2005b), perguntouse aos tutores "As correspondências enviadas pela Equipe de Capacitação e Apoio Pedagógico à Tutoria no período em que a disciplina foi oferecida, auxiliaram o seu trabalho de tutoria?". Como resposta, obteve-se 92\% de retorno positivo (fig.3). 
Figura.3: Índice de aproveitamento das correspondências do apoio pedagógico pelos tutores.

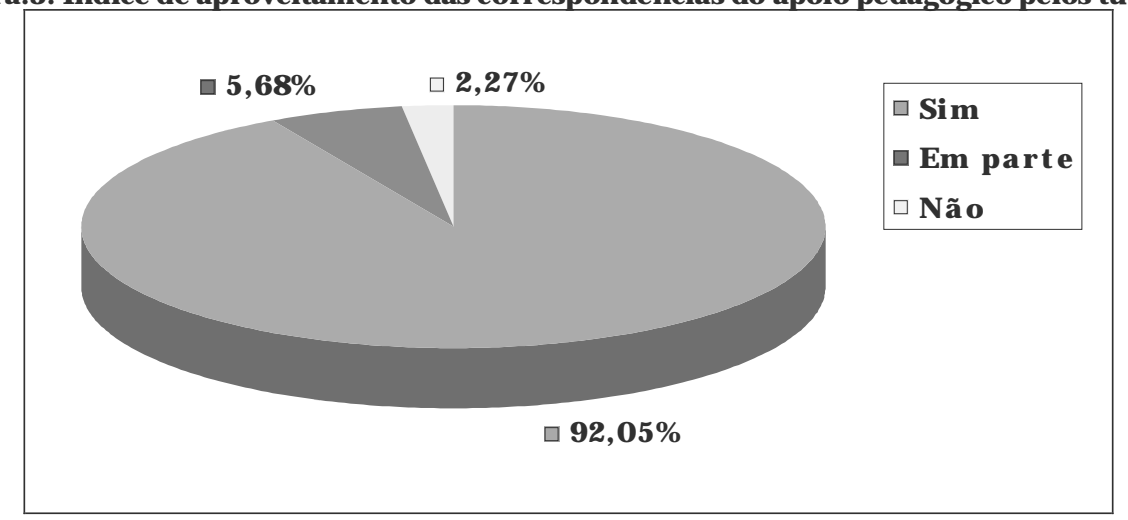

Os tutores enviam respostas para as mensagens recebidas da equipe, quase sempre no mesmo dia ou dia seguinte ao recebimento, com informações sobre os fatos, prontificando-se a resolvê-los, agradecendo pelas sugestões e apoio da equipe, solicitando orientações, dentre outras.

O exemplo a seguir, mostra um caso onde a tutora agradece a equipe pelo trabalho de acompanhamento.

Quadro 3: mensagem enviada a tutora parabenizando pelas ações e resposta da tutora agradecendo a equipe.

Mensagem enviada a tutora:

Olá Professora C.

"A vida tem a cor quevocê pinta!"

Esse pensamento de autor desconhecido nos leva a acreditar que a unisul virtual tem também a "cor" que pintamos...

Acompanhando a tutoria da sua disciplina de Gestão da Informação e do Conhecimento II, percebemos que o colorido é inspirado na "qualidade" de suas ações!

Parabéns!

Atenciosamente,

Equipede Capacitação e Apoio Pedagógico à tutoria.

$* * * * * * * * * * * * * * * *$

Resposta da Tutora

“Obrigada pela bonita mensagem. É bom muito bom saber que, assim como os alunos, os professores também não estão sozinhos.Abraço,

Profa. C'.

A preocupação do tutor em manter contato, citar o trabalho da equipe, informar sobre suas ações, demonstra uma boa relação entre estes agentes.

Em um outro depoimento (Unisul, 2005b), o tutor descreve como é visto o trabalho da equipe por ele e ressalta que a importância do apoio recebido durante a tutoria "Além da necessidade de orientação para eventuais alterações do sistema do 
AVA, na prática, éimportante a colaboração dada pela equipe de capacitação, para dirimir eventuais dúvidas, como tem ocorrido, para suprir a falta de experiência na tutoria [...]". Destaca também, como ele percebe as orientações da equipe para possíveis falhas, “[...] entendo importante que a equipe de capacitação, se verificar alguma falha do tutor, que o orientelogo, em tempo, para evitar que ocorra falha na disciplina em detrimento da Unisul edo aluno".

Mas durante este processo também surgem diferentes pontos de vista, estratégias de ação particulares de cada área do conhecimento e outros fatores a serem superados. É necessário entender que, "O acompanhamento neste enfoque implica ultrapassar a objetividade dos conhecimentos e integrar na interação os aspectos subjetivos como: o respeito, a confiança, a aceitação, o desprendimento, a humildade, de modo a desenvolver uma relação de reciprocidade" (Prado \& Valente, 2002, p.34).

Para todos os procedimentos de contato com o Professor Tutor, utilizam-se nas mensagens conteúdo e linguagem que demonstre a finalidade do trabalho da equipe, motive o Professor Tutor a empenhar-se ea agir em caso de necessidade.

Para cada turma que um professor tutor atua, é emitido um portfólio que consolida as suas ações e inclui uma análise geral de seu trabalho. Esta análise tem a função de subsidiar as ações dos coordenadores de curso no processo seletivo dos semestres seguintes e de auxiliar no diagnóstico do processo de trabalho como um todo, especialmente da metodologia e das necessidades de capacitação continuada dos tutores.

A partir da compilação de informações sobre as áreas que os tutores apresentam dificuldades, planeja-se e ofertam-se cursos, seminários e reuniões com foco na resolução das situações específicas.

Acredita-se que a capacitação e a prevenção são as formas mais adequadas de atuação da equipe e quanto menor é a necessidade de ações corretivas, tanto maior é a qualidade do processo.

\section{A CAPACITAÇÃO CONTINUADA E OS RUMOS DO SUPORTE AOS TUTORES}

“Vida, experiência e aprendizagem estão intrinsecamente entrelaçadas em nossa corporeidade, já que simultaneamente, vivemos, experimentamos, aprendemos e conhecemos, o que nos leva a compreender que o processo de aprendizagem é sempre integrado, amplo, multidimensional e muito mais rico do que se supunha até agora" (Moraes, 2002, p.11).

Além da capacitação inicial e acompanhamento pedagógico, a inserção novos cursos de formação continuada é uma outra ação desenvolvida para solidificar a competência dos tutores. Ela é necessária, uma vez que os tutores ou realizaram sua capaci- 
tação há algum tempo e estão desatualizados em relação às mudanças ocorridas na metodologia ou no Ambiente Virtual de Aprendizagem, ou necessitam de reforço pedagógico em questões observadas durante a execução de suas atividades.

Foi ofertada no final de 2005, uma oficina de Avaliação de Aprendizagem, que será repetida em maio de 2006. Ao ser questionado sobre a importância da formação continuada, um tutor citou que é essencial fazer oficinas como esta, relembrando do curso realizado, “Um exemplo foi a oficina sobre avaliação, achei muito produtivo e nos fez refletirmos sobre nossas práticas. Sinto a necessidade de fazer reflexões constantemente" (Unisul, 2005b).

Além desta também serão ofertadas atéjulho de 2006, mais duas oficinas de capacitação continuada para os professores tutores. A primeira, "O feedback na educação a distância - ferramentas desempenho e tutoria", visa auxiliar no processo de atendimento as dúvidas e correção de atividades a distância enviadas pelos alunos no Ambiente Virtual de Aprendizagem. A segunda oficina, "Como elaborar questões colaborativas", tem como objetivo auxiliar na criação de atividades inovadoras e que envolvam processos colaborativos, a serem utilizadas nos cursos a distância. Ambas as oficinas serão ofertadas em duas versões: presencial e a distância.

A formação continuada é uma modalidade que visa complementar a formação inicial, de forma que o professor tutor, em atuação, possa refletir sobre as suas ações junto com a equipe de formadores e com seus colegas, repensando a sua prática pedagógica.

Segundo Prado\&Valente (2003, p. 46), neste tipo de formação os docentes “[...] compartilham com seus pares, formador e especialistas sua atuação com os alunos, seus questionamentos, incertezas, dúvidas, análises e conquistas". Ao trazer as experiências para o espaço de formação, o ambiente de aprendizagem é enriquecido e podem-se realizar reflexões conjuntas sobre o conhecimento localizado de uma prática a ser estudada e compreendida.

Todas as acões que envolvem a atividades de tutoria objetivam a qualidade na Educação a Distância da UnisulVirtual. Uma vez capacitados, os Tutores deverão transpor aquilo que foi aprendido no curso para as suas aulas, sabendo que, durante a sua atuação, poderão contar com uma equipe para acompanhá-los e auxiliá-los.

Acredita-se que o retorno do trabalho realizado têm sido positivo e a afetividade nas relações entre os agentes do sistema tutorial, especialmente com os Tutores é gratificante, sendo muitas vezes, demonstrada por eles de forma explícita (quadro 4): 
Quadro 4: Trecho da mensagem enviada pelo Tutor F.M.G.

"Caro Coordenador e Equipe da Unisul Virtual

Quando tive a primeira oportunidade de conhece o "Ensino Virtual" não imaginava tamanha satisfação em fazer parte desta equipe, estava em Araranguá em uma aula de capacitação para professores, na qual tive o prazer que conhecer o Prof. ... que despertou um anseio pelo ensino virtual, no qual agradeço muito a ele.

Sou um novato, recentemente contrato pelo coordenador Prof. ..., que no qual, deu um voto de confiança em meu trabalho, tive até agora três experiências, uma foi em Salvador, outra foi em recife, porém a de São Paulo foi extraordinária.

No dia 04 de setembro, estava em São Paulo, dando a aula de revisão, (pequena palestra sobre o assunto abortado virtualmente, que na ocasião conseguir cativar a maioria dos alunos durante a aula e quando no final desta... fui aplaudido de pé, 85 pessoas presentes no qual tinham um olhar de satisfação, me arrepiei... literalmente... rsrsrs, foi minha primeira vez.

Em minha avaliação consegui surpreendê-los. Estou iniciando uma nova disciplina [...] vou tentar novamente surpreendêlos.

Gostaria de repassá-los os alguns dos e-mails recebidos na semana seguinte, pois isso é um resultado nosso, da Equipe Unisul Virtual, que está conseguindo surpreender a todos, segue abaixo [...].

Cordialmente,

Prof...”.

Sabe-se por outro lado que, apesar dos avanços nas atividades, muitos procedimentos ainda necessitam de melhoria.

Um dos pontos observados na experiência vivida pela autora e durante as investigações para este trabalho é a dificuldade de acompanhar o crescimento da UnisulVirtual e ao mesmo tempo, manter a personalização no contato com os tutores. Sabe-se que isto é essencial na continuidade da relação afetiva e de confiança mantida até o momento.

Um outro ponto observado é a necessidade de apresentar uma análise mais qualitativa do desempenho dos tutores, especialmente no que diz respeito ao teor e linguagem nas mensagens de contato com os alunos. Um exemplo disto é a análise de como o tutor avalia os alunos nas atividades obrigatórias a distância. Encontra-se hoje uma diversidade neste procedimento que é saudável e natural no estilo de cada docente, mas também se observa dificuldades dos tutores em lidar com conflito, com cópias de trabalhos, de apresentarem um feedback mais detalhado ao aluno, dentre outras.

Deve-se registrar o maior número possível de variáveis quantitativas e qualitativas no desempenho do tutor. Com isto, projetar ações pontuais das necessidades de intervenção da equipe ou da oferta de novas capacitações. O primeiro passo estará sendo dado no mês de maio de 2006, quando a equipe passará a fazer a pelo menos três registros descritivos de desempenho: no inicio, durante eapós a oferta da disciplina. 
Ao fazer um panorama geral até o momento, observa-se que todas as ações e resultados são conseqüência de um trabalho em equipe, coeso e que compartilha de um objetivo comum: a qualidade no processo de ensino-aprendizagem da EaD na UnisulVirtual.

\section{NOTAS}

1. Fonte: http://www.virtual.unisul.br

2. Uma turma corresponde ao grupo de alunos que estão matriculados em uma disciplina, agrupados em uma sala no Ambiente Virtual de Aprendizagem. Durante um semestre um aluno estará presente, na média, em seis turmas.

3. O período de plantão pedagógico é considerado do primeiro dia útil após a data final de oferta da disciplina até a avaliação presencial final. Neste período o professor tutor deve acessar o AVA ao menos uma vez por semana para responder eventuais dúvidas dos alunos.

\section{REFERENCIAS BIBLIOGRÁFICAS}

Castells, M. (1999) A sociedade em rede. São Paulo: Paz eTerra.

Hernandes, V.K (2005). Formação de professores: confluências internas e externas [en línea]. Diponible en: http:// www.divertire.com.br/artigos/vk achar1htm [consulta 2005, 16 de setembro].

Moraes, M.C. (2002). Educação a distância: fundamentos e práticas. Campinas, SP: UNICAMP/ NIED.

Sartori, A.S.; Roesler, J. (2005). Educação Superior a Distância: gestão da aprendizagem e da produção de materiais didáticos impressos e on-line. Tubarão. Ed. Unisul.

Roesler, J ; Flores, A.M.; Costa, A. (2005). Prática docente e novas tecnologias: livro didático. Palhoça (SC): UnisulVirtual.

Prado, M.E.B.B; Valente, J.A. (2003). A formação na ação do professor: uma abordagem na e para uma nova prática pedagógica. In: VALENTE, J.A. (Org). For- mação de educadores para o uso da informática na escola. Campinas, SP: UNICAMP/ NIED, 21-38.

UNISULVIRTUAL (2005a). Guia do Professor Tutor. Palhoça (SC): UnisulVirtual.

UNISULVIRTUAL (2005b). A UnisulVirtual sob a ótica do tutor: tabulação e análise dos dados referente ao questionário online aplicado aos tutores que atuaram em 2005b. Palhoça (SC): UnisulVirtual.

UNISULVIRTUAL (2006). Relatório do processo de capacitação de tutores de 2000 a 2005. Palhoça (SC): UnisulVirtual.

Valentini, C.B; Soares, E.M.S. (2006) Sobre ambientes virtuais de aprendizagem [en ínea]. Disponible en: http://hermes.ucs.br/lavia/introduc liv ro.html [consulta 2006, 15 deabril].

Vianney, J .; Torres, P. L.; Silva, E. (2003) A Universidade Virtual no Brasil: o ensino superior a distância no país. Tubarão: Ed. Unisul. 


\title{
PALABRAS CLAVE
}

Educação a Distância, Qualidade, Tutoria, Capacitação.

\section{KEY WORDS}

Distance education, quality, tutoring, training.

\section{PERFIL ACADÉMICO DE LA AUTORA}

Angelita Marçal Flores é graduada em Processamento de Dados (1989), especialista em Informática aplicada (1996) e Mestre em Educação (2001). Há 14 anos trabalha no quadro docente da Unisul, é professora nas disciplinas de informática básica e aplicada dos cursos presenciais. As investigações que realiza envolvem as áreas de informática aplicada à educação, educação a distância, inclusão digital e análise sóciotécnica.. Integra a cinco anos a Equipe de Capacitação a Apoio Pedagógico à Tutoria na UnisulVirtual, sendo também tutora e autora de materiais didáticos para cursos a distância.

Dirección postal:

\author{
Rua Fernando Ferreira de Mello, 376. \\ Bloco 01 - Apto 02. \\ Bom Abrigo - Florianópolis - SC - Brasil. \\ CEP: 88085-260 \\ E-mail: angelita@unisul.br
}

Fecha recepción del artículo: 14. 02. 2006

Fecha aceptación del artículo: 30. 02. 2006 